\title{
Scaling the criteria to be considered in determining exam anxiety by pairwise comparison method
}

\author{
Hasibe Yahsi Sari ${ }^{1}{ }^{*}$, Duygu Anil ${ }^{2}$
}

${ }^{1}$ Hacettepe University, Faculty of Education, Department of Educational Sciences, Ankara, Turkiye.

\author{
ARTICLE HISTORY \\ Received: July 01, 2021 \\ Revised: Dec. 12, 2021 \\ Accepted: Jan. 31, 2022 \\ Keywords: \\ Exam anxiety, \\ Pairwise comparison, \\ Thurstone, \\ Equation of case III, \\ Scaling.
}

\begin{abstract}
In this study, it was aimed to scale the importance level of the criteria that can be taken into consideration in determining the exam anxiety of $8^{\text {th }}$ grade students by means of pairwise comparison. Descriptive survey model was used in the research. The study group of the research consists of $1008^{\text {th }}$ grade students studying at a randomly selected secondary school in Kilis. The data collection tool was a questionnaire in which the students in the study group were compared in pairs, that consisted of six criteria that affect exam anxiety, including the thought of failing in lessons, the effect of the social environment (family, friends and relatives), students's self-perceptions, teacher attitudes, social and physical characteristics of the school, and the thought of not being prepared for exams adequately. Data analysis was performed on a full data matrix by using equation of case III. As a result of the research, the first two criteria that most affect the exam anxiety of $8^{\text {th }}$ grade students are respectively; social and physical characteristics of the school and how students see themselves. These stimulators are respectively followed by the idea of failing in lessons and the effect of the social environment. The two criteria, which they think are the least effective on exam anxiety, are the attitudes of teachers and not being prepared for exams adequately.
\end{abstract}

\section{INTRODUCTION}

Anxiety is an important emotion that affects the processes that can be called milestones in people's lives. Anxiety comes to the fore especially in our academic life. Unfortunately, today, this feeling is seen frequently even at a very young age. The reason for this is that children take exams at an early age and both parents and students attribute more importance to these exams than necessary. Mandler and Sarason (1952) defined exam anxiety as a feeling of inadequacy and helplessness, abnormal somatic reactions, fear of punishment, loss of dignity, and the desire to leave the anxiety-provoking environment.

Exam anxiety is a set of multidimensional negative phenomena that may occur before or during the exam (Basol, 2017). There is a need for research to determine how and how much the academic success and quality of life of students are affected due to exam anxiety, and which factors affect exam anxiety more. Basol \& Zabun (2014), in their study, found to what extent participation in private exam preparation courses, multidimensional perfectionism, parental 
attitudes and exam anxiety explained $8^{\text {th }}$ grade students' SBS success levels. According to their research results, the most important predictor in determining the success level of a student is attending private preparation courses, while other predictors are a perfectionist attitude by the parents and the level of exam anxiety of the students.

Students push their cognitive capacities in order to enter qualified high schools and maximize their talents and skills. This situation creates exam anxiety for students. Hembree (1988) analyzed 562 studies in his meta-analysis on exam anxiety. As a result of the research, he stated that exam anxiety is directly related to the fear of negative evaluation, alertness and other types of anxiety.

Exam anxiety is a frequently seen feeling especially in $8^{\text {th }}$ and $12^{\text {th }}$ grades (Bulut, 2010; Duman, 2008; Kayapinar, 2006; Kaya \& Savrun, 2015; Kesici \& Asilioglu, 2017). In his study, Duman (2008) found that there was a significant relationship between state trait anxiety and exam anxiety levels and parental attitudes of $8^{\text {th }}$ grade students. Güler and Cakir (2013) analyzed the role of gender, irrational beliefs and parental attitudes on $12^{\text {th }}$ grade students' exam anxiety levels. According to the research results, it was seen that only the strict control attitude perceived from the mother significantly predicted the exam anxiety total delusion and effectiveness scores. Social environment is defined in the literature as; family, friends, school and place of residence (Coban, 2009), society, peer groups, school, professional environment (Yelken, 2011). Therefore, in this study, family, friends and relatives are considered as the effect of the social environment. Zeidner (1998) revealed that negative feelings about exam anxiety could manifest as an individual having negative thoughts about himself and feeling panic. Cakmak, Sahin, and Akinci-Demirbas (2017) analyzed the relationship between exam anxiety and self-esteem of $7^{\text {th }}$ and $8^{\text {th }}$ grade students and searched whether some variables made a difference in exam anxiety and self-esteem scores. It was found that there was a negative significant relationship between exam anxiety and self-esteem.

The sub-dimensions in the scales also reveal the factors that affect the exam anxiety of individuals. For example, the sub-dimensions of the Exam Anxiety Scale for Children adapted to our language by Aydin and Bulgan (2017) are thoughts, off-task behaviors and autonomous reactions. Various measurement tools were used to measure the level of exam anxiety in studies. Some of these scales are: Westside Exam Anxiety Scale (Driscoll, 2007), Spielberger's Exam Anxiety Scale (Spielberger, 1980), Children's Exam Anxiety Scale (Wren \& Benson, 2004). These measurement tools, which were adapted into Turkish, were used in many studies (Bacanl1 \&Driver, 2006; Basol \& Zabun, 2014; Delioglu, 2017; Duman, 2008; Kavakci, Güler \& Cetinkaya, 2011; Totan \& Yavuz, 2009; Tugan, 2015). While studies about exam anxiety scale development, adaptation and application are frequently encountered, the lack of scaling studies necessitated this study. Based on the studies in the literature, six criteria affecting exam anxiety were determined: the thought of failing in the lessons, the effect of the social environment (family, friends, relatives), students's self-perceptions, teacher attitudes, the social and physical characteristics of the school, and the thought of not being prepared for exams adequately.

\subsection{Scaling}

Scaling is needed to measure all emotions, situations and phenomena. In order to measure affective features, we need a measurement tool. We use scales to determine the importance of the qualities we will use in a measurement tool, to develop a measurement tool that serves the purpose of measurement and whose measurement results do not change over time. We develop these scales using various scaling techniques. According to Turgut and Baykul (1992), "The mathematical properties of the measurements obtained after the measurement based on the formal structure of the measurement attributes are called scales". Scaling aims to obtain more sensitive and better measurable standard scales by using different statistical methods under certain assumptions with the data obtained from observer judgments or subject reactions, about 
psychological variables whose physical properties are unknown and whose physical dimensions cannot be defined, and which do not have standard measurement tools (Anil \& Inal, 2017). With scaling, measurement and comparison are made between real life and the world of perception. In scaling, first of all, the scale is developed by assigning numbers to psychological objects, and then individuals are placed on the developed scale (Anil \& Inal, 2017). There are many scaling techniques. Some of these are: scaling with pairwise comparisons, scaling with ranking judgments, scaling with classification judgments, scaling with absolute judgments, scaling with rank sums, and multidimensional scaling. In the study, the scaling technique with pairwise comparisons was used.

\subsubsection{Scaling with Pairwise Comparisons}

Scaling with pairwise comparisons, one of the scaling techniques, was developed by Thurstone. The scaling method with pairwise comparisons is used when stimuli can be given to the respondents in pairs. In this method, observers make a response at the end of the process of distinguishing the stimulus. When an observer observes a $U_{j}$ stimulus at different times and situations, he may perceive it differently. The reason for this is the instantaneous changes of the observer. These changes cause errors in discrimination judgments. This error is expressed by this equation:

$$
\begin{aligned}
& \qquad s_{j}^{\prime}=s_{i j}+e_{i j} \\
& (\mathrm{i}=1,2, \ldots, \mathrm{N}) \\
& (\mathrm{j}, \mathrm{k}=1,2, \ldots, \mathrm{K}) \\
& s_{j}^{\prime}: \text { The value of the } \mathrm{Uj} \text { stimulus in the psychological dimension. } \\
& s_{i j}: \text { The perceived value of the Uj stimulus by the observer } \mathrm{i} . \\
& e_{i j}: \text { Error of observer } \mathrm{i} \text { in discrimination judgment of } s i j
\end{aligned}
$$$$
\text { Equation } 1
$$

It is assumed that the $e_{i j}$ error here is random and $\sum e_{i j}=0$ (Turgut and Baykul, 1992).

\subsection{Comparative Judgement Law}

Thurstone (1927) showed the difference between the scale values of two stimuli, $\mathrm{j}$ and $\mathrm{k}$, according to comparative judgement law in the psychological dimension, with equation 2 :

$$
S_{j}-S_{k}=z_{j k} \sqrt{\sigma_{j}^{2}+\sigma_{k}^{2}-2 \cdot r_{j k} \cdot \sigma_{j} \cdot \sigma_{k}}
$$

Equation 2

Five equations of case are used for the application of comparative law. The equation of case I has no solution. Since the number of unknowns is more than the number of equations, this case is known as the ideal case and is unsolvable. In the equation of case III, scaling is possible if $\mathrm{N}$ discrimination judgments are given for each of the $\mathrm{K}$ stimuli. This is the ideal case and has no solution. In the equation of case III, the correlations in equation 2 are regarded to be zero and the following equation is obtained:

$$
S_{j}-S_{k}=z_{j k} \sqrt{\sigma_{j}^{2}+\sigma_{k}^{2}}
$$

Equation 3

If the standard deviations of the discrimination judgments of the observers in the equation of case IV are very close to each other, the following equation is obtained.

$$
S_{j}-S_{k}=z_{j k} \cdot 0,707 \cdot\left(\sigma_{j}^{2}+\sigma_{k}^{2}\right.
$$

Equation 4

Equation of case $\mathrm{V}$ is the most used one. In this case, the correlation is assumed to be zero. It is also assumed that the stimuli discrimination distributions of all observers will be equal to each other and at a constant value in a scaling trial. 


$$
S_{j}-S_{k}=z_{j k}
$$

Equation 5

\subsection{Purpose of the Study}

In this study, it was aimed to scale the criteria that can be taken into consideration in determining the exam anxiety of $8^{\text {th }}$ grade students with the pairwise comparison method. In the study, the question "How is the ranking of the criteria that can be taken into consideration in determining the exam anxiety of $8^{\text {th }}$ grade students according to the scale values?" was tried to be answered.

As it is known, $8^{\text {th }}$ grade students take the high school entrance exam every year. This exam, which has the importance to affect the future of students, creates anxiety (Bacanli \& Drive, 2016; Duman, 2008). With this research, it is thought that revealing the psychometric importance levels of the factors that increase students' exam anxiety is important both in terms of literature and educational practices. Thus, students are given the necessary preventive guidance and psychological counseling in terms of exam anxiety, and exam anxiety is brought to the optimum level.

There are limited studies in the literature to determine the factors affecting test anxiety (Genc, 2016). Although there are studies using scaling methods in the literature (Anil, Taymur \& Oztemur, 2017), there isn't any study on test anxiety. It is a unique research in terms of the method used and in terms of the absence of scaling studies with the pairwise comparison method in determining the criteria affecting test anxiety.

\section{METHOD}

In this section, the research model, study group, data collection tools and data analysis are explained.

\subsection{Research Model}

In the study, it was aimed to scale the criteria affecting the exam anxiety of $8^{\text {th }}$ grade students by using pairwise comparisons. The model of the research is descriptive survey. This model is a quantitative research technique that aims to determine certain characteristics of the universe or sample (Büyüköztürk et al., 2008).

\subsection{Study Group}

The study group of the research consists of $1008^{\text {th }}$ grade students from a randomly selected secondary school in Kilis.

\subsection{Data Collection Tools}

While preparing the data collection tool, the literature was searched and the studies were analyzed. According to studies in the literature, 10 factors affecting students' test anxiety were determined. In order to regulate the number of factors, a pilot application was made to the students. In addition to this pilot application, in order to examine the place of test anxiety in the literature and the psychometric properties of the measurement tool, expert opinion was obtained from a total of 6 academicians (a professor of Measurement and Evaluation in Education, two doctoral faculty members of Psychological Counseling and Guidance, and three research assistants, one of whom is Measurement and Evaluation in Education, and two of which are Psychological Counseling and Guidance). After the relevant eliminations, it was decided that these 10 factors would be too much for the students. 6 out of 10 items were selected. Finally, six factors (the thought of failing in the lessons, the effect of the social environment, students's self-perceptions, teacher attitudes, the social and physical characteristics of the school, the thought of not being prepared for the exams adequately) that affect the exam anxiety of the $8^{\text {th }}$ grade students were arranged so that a pairwise comparison could be made. All factors were explained during the data collection phase. For example, it has been stated that the influence of 
the social environment refers to family, friends and relatives. During the data collection process, the measurement tool was applied to the students personally.

\subsection{Data Analysis}

Scaling approach with pairwise comparison method was used in data analysis. The basis of this technique is the comparative judgement law. In the pairwise comparison method, observers are asked to choose which of the pairs of stimuli has priority. Non-discrimination judgments are not allowed (Turgut \& Baykul, 1992). In the research, Thurstone's comparative judgment law was applied with the full data matrix in the equation of case V. First, the frequency matrix $(F)$ is calculated for $U_{k}>U_{j}$. In this matrix, the column with the smallest frequency values is the most preferred factor among the compared factors. After the frequency matrix is created, the values in this matrix are divided by the number of observers. The new matrix obtained is the ratio matrix $(\mathrm{P})$. Then the $\mathrm{z}$ value of each ratio in the ratio matrix is calculated and converted to the unit normal deviations matrix $(\mathrm{Z})$. The mean of all columns in the unit normal deviations matrix is found. After taking the average of each column, the scale values $\left(\mathrm{S}_{\mathrm{j}}\right)$ of the criteria are calculated. In order to obtain a nominal zero point in the scale, standardized scale values $\left(\mathrm{S}_{\mathrm{c}}\right)$ are obtained by adding the absolute value of the smallest $\mathrm{z}$ value among the calculated averages to the mean in each column. At the end of all these processes, the standardized scale values are displayed on the numerical axis and ranked (Turgut \& Baykul, 1992).

After the scale values were calculated and ranked on the numerical axis, the internal consistency of the scaling needs to be analyzed in order to check whether the assumptions valid for Thurstone's comparative judgment law equation of case $\mathrm{V}$ are correct and whether the observers are careful in their judgments. Internal consistency of scaling is determined by analyzing how similar the observed $p_{\mathrm{jk}}$ and obtained $\mathrm{p}_{\mathrm{jk}}$ ratios are (Guilford, 1954). For this purpose, the internal consistency of the scale values was analyzed. Internal consistency value was calculated with the chi-square $\left(\chi^{2}\right)$ test. The Chi-Square value at 10 degrees of freedom was found to be 31.48. If the chi-square table value is for $s d=10$, the Chi-Square value is 18.307. Since $31.48>18.307$, it was concluded that this value was significant at the level of 0.05 with 10 degrees of freedom. In such cases, it is recommended to use the case III, which does not require the assumption that the discrimination variances are equal for all stimuli (Turgut \& Baykul, 1992).

After the results, the equation of case III was applied. First, the variances of the discrimination distributions are estimated for each stimulus ( $Z$ matrix). With the values obtained, the matrix of variance sums is reached. By taking the square roots of the elements of this matrix, the square root matrix of the variance sums is formed. The $S$ matrix is obtained by multiplying the $Z_{j k}$ values obtained from the $\mathrm{Z}$ matrix with the square root matrix of the variance sums. The mean values are obtained by taking the column averages of the $S$ matrix. Finally, the scale values are calculated by shifting the smallest mean value to zero. The order of the calculated scale values is shown on the numerical axis.

\section{FINDINGS}

At this stage of the research, the factors affecting the exam anxiety of $8^{\text {th }}$ grade students were first scaled with the equation of case V. The Chi-square value calculated for the internal consistency of the scale values using the Transformed Difference Squares Matrix was obtained as 31.48. This value is greater than the Chi-square table value (Chi-Square $=18.307$ for $s d=10$ ). In other words, the Chi-square value obtained is statistically significant at the level of $a=0.05$. According to this result, the data do not correspond to the assumptions of case $\mathrm{V}$ and pairwise comparison. In this case, Guilford (1954, p.154) recommends the use of the case III. Therefore, the calculations were continued with the equation of case III. 
While reporting the results of the analysis, the factors affecting the exam anxiety of the students were coded as follows:
A: The thought of failing in lessons,
B: The effect of the social environment,
C: Students's self-perceptions,
D: Teacher attitudes,
E: Social and physical characteristics of the school,
F: The thought of not being prepared for exams adequately.

\subsection{Scaling by Equation of Case $\mathrm{V}$}

In the study, 100 students were asked to compare 6 factors (stimulus) given to them in pairs. The frequency values of the stimuli after the pairwise comparison using case $\mathrm{V}$ are given in Table 1.

Table 1. Frequency matrix.

\begin{tabular}{|c|c|c|c|c|c|c|c|}
\hline \multicolumn{8}{|c|}{$\mathrm{U}_{\mathrm{j}}$} \\
\hline$U_{k}$ & A & B & $\mathrm{C}$ & D & E & F & Total \\
\hline A & & 31 & 31 & 61 & 34 & 74 & 231 \\
\hline B & 69 & & 33 & 52 & 33 & 74 & 261 \\
\hline $\mathrm{C}$ & 69 & 67 & & 56 & 40 & 78 & 310 \\
\hline D & 39 & 48 & 44 & & 26 & 66 & 223 \\
\hline E & 66 & 67 & 60 & 74 & & 72 & 339 \\
\hline $\mathrm{F}$ & 26 & 26 & 22 & 34 & 28 & & 136 \\
\hline Total & 269 & 239 & 190 & 277 & 161 & 364 & 1500 \\
\hline
\end{tabular}

The values in Table 1 show the number of participants who preferred column stimuli to row stimuli. For example, the number of participants who preferred stimulus B to stimulus A is 31 . In this matrix, the total number of the opposite diagonals gives the number of observers, and this is 100 . By proportioning the values in the frequency matrix to the number of observers, the ratio matrix in Table 2 is obtained.

Table 2. Ratio matrix.

\begin{tabular}{|c|c|c|c|c|c|c|c|}
\hline \multicolumn{8}{|c|}{$\mathrm{U}_{\mathrm{j}}$} \\
\hline$U_{k}$ & A & $\mathrm{B}$ & $\mathrm{C}$ & $\mathrm{D}$ & $\mathrm{E}$ & $\mathrm{F}$ & Total \\
\hline A & 0 & 0.31 & 0.31 & 0.61 & 0.34 & 0.74 & 2.31 \\
\hline B & 0.69 & 0 & 0.33 & 0.52 & 0.33 & 0.74 & 2.61 \\
\hline $\mathrm{C}$ & 0.69 & 0.67 & 0 & 0.56 & 0.4 & 0.78 & 3.1 \\
\hline $\mathrm{D}$ & 0.39 & 0.48 & 0.44 & 0 & 0.26 & 0.66 & 2.23 \\
\hline $\mathrm{E}$ & 0.66 & 0.67 & 0.6 & 0.74 & 0 & 0.72 & 3.39 \\
\hline $\mathrm{F}$ & 0.26 & 0.26 & 0.22 & 0.34 & 0.28 & 0 & 1.36 \\
\hline Total & 2.69 & 2.39 & 1.9 & 2.77 & 1.61 & 3.64 & 15 \\
\hline
\end{tabular}

Then, to find the $\mathrm{z}$ values of the values in the P ratios matrix, the NORMTERS function, which gives the inverse of the standard normal cumulative distribution in Excel, is used, and then it is passed to the unit normal deviations matrix. The unit normal deviations matrix is shown in Table 3. 
Table 3. Unit normal deviations matrix.

\begin{tabular}{lllllll}
\hline & & \multicolumn{2}{c}{$\mathrm{U}_{\mathrm{j}}$} & & $\mathrm{D}$ & $\mathrm{F}$ \\
\hline & $U_{k}$ & $\mathrm{~A}$ & $\mathrm{~B}$ & $\mathrm{C}$ & $\mathrm{D}$ & $\mathrm{E}$ \\
\hline $\mathrm{A}$ & & -0.496 & -0.496 & 0.279 & -0.412 & 0.643 \\
$\mathrm{~B}$ & 0.496 & & -0.44 & 0.05 & -0.44 & 0.643 \\
$\mathrm{C}$ & 0.496 & 0.44 & & 0.151 & -0.253 & 0.772 \\
$\mathrm{D}$ & -0.279 & -0.05 & -0.151 & & -0.643 & 0.412 \\
$\mathrm{E}$ & 0.412 & 0.44 & 0.253 & 0.643 & & 0.583 \\
$\mathrm{~F}$ & -0.643 & -0.643 & -0.772 & -0.412 & -0.583 & \\
\hline Total & 0.482 & -0.309 & -1.606 & 0.711 & -2.331 & 3.053 \\
\hline Mean & 0.08 & -0.052 & -0.268 & 0.119 & -0.389 & 0.509 \\
\hline Sj & 0.469 & 0.337 & 0.121 & 0.508 & 0 & 0.898 \\
\hline
\end{tabular}

In the unit normal deviation matrix, the mean of the distribution is zero and the standard deviation is one. In this matrix, elements that are symmetric about the main diagonal are opposite in sign but equal in absolute value. The column totals, column averages and scale values $\left(\mathrm{S}_{\mathrm{j}}\right)$ of the $\mathrm{Z}$ unit normal deviations matrix are calculated, respectively. While calculating the scale values $\left(\mathrm{S}_{\mathrm{j}}\right)$, the starting point is shifted to be zero. The $\mathrm{S}_{\mathrm{j}}$ values obtained from this matrix give the scale values of the stimuli for the equation of case $\mathrm{V}$. The found scale values are shown in Figure 1. Factors scale values and stimulus orders affecting $8^{\text {th }}$ grade students' exam anxiety according to equation of case $\mathrm{V}$ results are shown in Table 4.

Figure 1. Scale values of the factors affecting the exam anxiety of $8^{\text {th }}$ grade students by equation of case $V$.

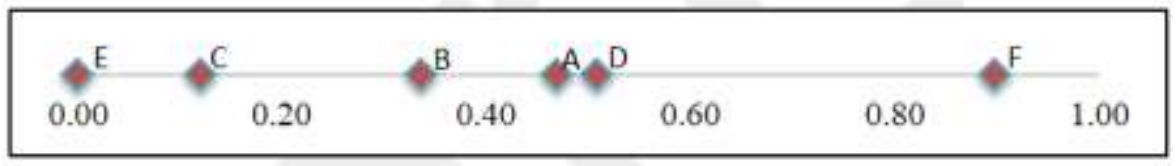

Table 4. Factors scale values and stimulus orders affecting $8^{\text {th }}$ grade students' exam anxiety according to equation of case $V$ results.

\begin{tabular}{lcc}
\hline Factors & Scale Values & Stimulus Orders \\
\hline A- Thought of failing in lesson & 0.469 & 4 \\
B- The effect of the social environment & 0.337 & 3 \\
C-Students's self-perceptions & 0.121 & 2 \\
D-Teacher attitudes & 0.508 & 5 \\
E- Social and physical characteristics of the school & 0 & 1 \\
F- Thought of not being prepared for exams adequately & 0.898 & 6 \\
\hline
\end{tabular}

Table 5. Transformed difference squares matrix.

\begin{tabular}{lllllll}
\hline & $\mathrm{A}$ & $\mathrm{B}$ & $\mathrm{C}$ & $\mathrm{D}$ & $\mathrm{E}$ & $\mathrm{F}$ \\
\hline $\mathrm{A}$ & 2025 & 66.007 & 10.727 & 29.568 & 1.485 & 21.6 \\
$\mathrm{~B}$ & 66.007 & 2025 & 24.864 & 7.629 & 5.22 & 3.013 \\
$\mathrm{C}$ & 10.727 & 24.864 & 2025 & 28.546 & 9.084 & 0.005 \\
$\mathrm{D}$ & 29.568 & 7.629 & 28.546 & 2025 & 8.571 & 0.233 \\
$\mathrm{E}$ & 1.485 & 5.22 & 9.084 & 8.571 & 2025 & 41.901 \\
$\mathrm{~F}$ & 21.6 & 3.013 & 0.005 & 0.233 & 41.901 & 2025 \\
\hline Total & 258.453 & & & & & \\
Chi-square & 31.48026797 & & & & & \\
sd & 10 & & & & & \\
\hline
\end{tabular}


In Table 5, the internal consistency of the scale values calculated with the equation of case $\mathrm{V}$ was tested with the chi-square statistics and the chi-square was found to be 31.48 . This value is significant at the 0.05 level with 10 degrees of freedom. According to this result, the data does not satisfy the assumptions of the equation of case $\mathrm{V}$ or pairwise comparisons method. For this reason, calculations were continued by using the equation of case III.

\subsection{Scaling by Equation of Case III}

When the data does not satisfy the assumptions of the equation of case $\mathrm{V}$ or the pairwise comparison method, the calculations should be continued using the equation of case III. According to the results obtained in Table 5, the assumptions do not satisfy. For this reason, scaling was continued with the equation of case III. In Table 6 , observer variances were estimated with the help of $\mathrm{Z}$ matrix values.

Table 6. Z Matrix and estimation of observer variances.

\begin{tabular}{lllllll}
\hline & \multicolumn{7}{c}{$\mathrm{U}_{\mathrm{j}}$} \\
\hline$U_{k}$ & $\mathrm{~A}$ & $\mathrm{~B}$ & $\mathrm{C}$ & $\mathrm{D}$ & $\mathrm{E}$ & $\mathrm{F}$ \\
\hline $\mathrm{A}$ & & -0.496 & -0.496 & 0.279 & -0.412 & 0.643 \\
$\mathrm{~B}$ & 0.496 & & -0.44 & 0.05 & -0.44 & 0.643 \\
$\mathrm{C}$ & 0.496 & 0.44 & & 0.151 & -0.253 & 0.772 \\
$\mathrm{D}$ & -0.279 & -0.05 & -0.151 & & -0.643 & 0.412 \\
$\mathrm{E}$ & 0.412 & 0.44 & 0.253 & 0.643 & & 0.583 \\
$\mathrm{~F}$ & -0.643 & -0.643 & -0.772 & -0.412 & -0.583 & \\
\hline $\mathrm{Vj}$ & 0.47 & 0.454 & 0.348 & 0.342 & 0.137 & 0.117 \\
$\mathrm{KVj}$ & 2.82 & 2.724 & 2.088 & 2.052 & 0.822 & 0.702 \\
$1 / \mathrm{KVj}$ & 0.355 & 0.367 & 0.479 & 0.487 & 1.217 & 1.425 \\
$\Sigma 1 / \mathrm{KVj}$ & 4.33 & & & & & \\
$\mathrm{~K} . \mathrm{C}$ & 2.771 & & & & & \\
$\sigma \mathrm{j}$ & -0.017 & 0.017 & 0.327 & 0.35 & 2.371 & 2.947 \\
$\sigma \mathrm{j} 2$ & 0 & 0 & 0.107 & 0.123 & 5.622 & 8.685 \\
\hline
\end{tabular}

The variance values obtained for each stimulus in the last row of Table 6 were calculated by squaring the standard shifts in the last row. Then, these variances are summed in pairs to form the variance sum matrix in Table 7 . By taking the square root of the values in Table 7, the square root matrix of the variance sums in Table 8 is reached.

Table 7. Variance sum matrix.

\begin{tabular}{llcclccc}
\hline & \multicolumn{7}{c}{$\mathrm{U}_{\mathrm{j}}$} \\
\hline & & $\mathrm{A}$ & $\mathrm{B}$ & $\mathrm{C}$ & $\mathrm{D}$ & $\mathrm{E}$ & $\mathrm{F}$ \\
$U_{k}$ & & 0 & 0 & 0.107 & 0.123 & 5.622 & 8.685 \\
\hline $\mathrm{A}$ & 0 & 0 & 0 & 0.107 & 0.123 & 5.622 & 8.685 \\
$\mathrm{~B}$ & 0 & 0 & 0 & 0.107 & 0.123 & 5.622 & 8.685 \\
$\mathrm{C}$ & 0.107 & 0.107 & 0.107 & 0.214 & 0.23 & 5.729 & 8.792 \\
$\mathrm{D}$ & 0.123 & 0.123 & 0.123 & 0.23 & 0.246 & 5.745 & 8.808 \\
$\mathrm{E}$ & 5.622 & 5.622 & 5.622 & 5.729 & 5.745 & 11.244 & 14.307 \\
$\mathrm{~F}$ & 8.685 & 8.685 & 8.685 & 8.792 & 8.808 & 14.307 & 17.37 \\
\hline
\end{tabular}


Table 8. Square roots of variance sums.

\begin{tabular}{llllll}
\hline \multicolumn{5}{c}{$\mathrm{U}_{\mathrm{j}}$} \\
\hline $\mathrm{A}$ & $\mathrm{B}$ & $\mathrm{C}$ & $\mathrm{D}$ & $\mathrm{E}$ & $\mathrm{F}$ \\
\hline 0 & 0 & 0.327 & 0.351 & 2.371 & 2.947 \\
0 & 0 & 0.327 & 0.351 & 2.371 & 2.947 \\
0.327 & 0.327 & 0.463 & 0.48 & 2.394 & 2.965 \\
0.351 & 0.351 & 0.48 & 0.496 & 2.397 & 2.968 \\
2.371 & 2.371 & 2.394 & 2.397 & 3.353 & 3.782 \\
2.947 & 2.947 & 2.965 & 2.968 & 3.782 & 4.168 \\
\hline
\end{tabular}

For the $\mathrm{S}$ matrix, the elements of the $\mathrm{Z}$ matrix and the square root of the variance sums are multiplied. The values above the diagonal of the $S$ matrix in Table 9 are obtained. Elements below the diagonal and elements above the main diagonal are opposite in sign and equal in absolute value. In the $\mathrm{S}$ matrix, scaling is completed, as in the $\mathrm{Z}$ matrix of the case $\mathrm{V}$, by averaging each column and shifting the smallest average value to zero.

Table 9. S Matrix.

\begin{tabular}{|c|c|c|c|c|c|c|}
\hline \multicolumn{7}{|c|}{$\mathrm{U}_{\mathrm{j}}$} \\
\hline$U_{k}$ & A & $\mathrm{B}$ & $\mathrm{C}$ & $\mathrm{D}$ & $\mathrm{E}$ & $\mathrm{F}$ \\
\hline A & 0 & 0 & -0.162 & 0.098 & -0.977 & 1.895 \\
\hline B & 0 & 0 & -0.144 & 0.018 & -1.043 & 1.895 \\
\hline $\mathrm{C}$ & 0.162 & 0.144 & 0 & 0.072 & -0.606 & 2.289 \\
\hline D & -0.098 & -0.018 & -0.072 & 0 & -1.541 & 1.223 \\
\hline $\mathrm{E}$ & 0.977 & 1.043 & 0.606 & 1.541 & 0 & 2.205 \\
\hline $\mathrm{F}$ & -1.895 & -1.895 & -2.289 & -1.223 & -2.205 & 0 \\
\hline Total & -0.854 & -0.726 & -2.061 & 0.506 & -6.372 & 9.507 \\
\hline Mean & -0.142 & -0.121 & -0.344 & 0.084 & -1.062 & 1.585 \\
\hline $\mathrm{S}_{\mathrm{j}}$ & 0.92 & 0.941 & 0.718 & 1.146 & 0 & 2.647 \\
\hline
\end{tabular}

In the $\mathrm{S}$ matrix, the principal diagonal elements are 0 . The $\mathrm{S}$ matrix elements are opposite in sign with respect to the main diagonal, but equal in absolute value, as in the $\mathrm{Z}$ unit normal deviations matrix. In Figure 2, the scale values calculated with the equation of case III are shown on the numerical axis.

Figure 2. Scale values of factors affecting $8^{\text {th }}$ grade students' exam anxiety by equation of case III.

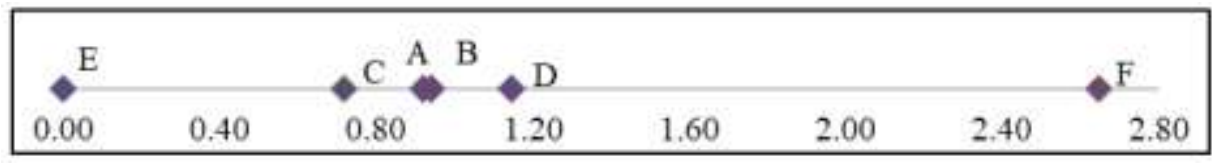

Table 10. Factors scale values and stimulus orders affecting $8^{\text {th }}$ grade students' exam anxiety according to equation of case III results.

\begin{tabular}{lll}
\hline Factors & Scale Values & Stimulus Orders \\
\hline A- Thought of failing in lesson & 0.92 & 3 \\
B- The effect of the social environment & 0.941 & 4 \\
C- Students's self-perceptions & 0.718 & 2 \\
D-Teacher attitudes & 1.146 & 5 \\
E- Social and physical characteristics of the school & 0 & 1 \\
F- Thought of not being prepared for exams adequately & 2.647 & 6 \\
\hline
\end{tabular}


When Table 10 is analyzed, it is seen that the first two criteria that most affect the exam anxiety of $8^{\text {th }}$ grade students are the social and physical characteristics of the school and students's selfperceptions, respectively. These stimulants are followed by the thought of failing in lessons and the effect of the social environment. The two criteria that they think affect exam anxiety the least are teacher attitudes and the thought of not being prepared for exams adequately. As a result of the research, it has been seen that two factors -the thought of failing in the lessons and the effect of the social environment- have a similar effect on test anxiety.

\section{DISCUSSION and CONCLUSION}

In this study, it was aimed to analyze the factors affecting the exam anxiety of $8^{\text {th }}$ grade students. In the scaling made for this purpose, first of all, the equation of case $\mathrm{V}$ of the pairwise comparison method was applied. Since the internal consistency of the results obtained was significant, the equation of case III was used.

According to the results of the research, the first two factors that most affect the exam anxiety of $8^{\text {th }}$ grade students are the social and physical characteristics of the school and how students see themselves, respectively. These stimulants are followed by the thought of failing in the lessons and the effect of the social environment. The two criteria that they think affect exam anxiety the least are teacher attitudes and the thought of not being prepared for exams adequately.

The second most important factor affecting students' exam anxiety is students's self-perceptions academically. Bozanoglu (2005) in his group guidance study based on cognitive-behavioral approach stated that there are significant differences in the relationships between academic motivation, academic self-esteem, academic achievement and exam anxiety. In this study, the fact that the factor's "students's self-perceptions" being in the second place supports the results academically. The effect of the social environment (family, friends and relatives) is in the third place. The positive effect of group guidance based on the cognitive-behavioral approach on exam anxiety levels explains the high level of effect of the social environment. Students tend to get support from their social environments in order to reduce their exam anxiety.

Turan-Basoglu (2007), in his study analyzing the relationship between exam anxiety and selfconfidence in adolescence, found that there is a negative correlation between exam anxiety and self-confidence of successful students. How students see themselves is related to their selfconfidence. As a result of the current study, its second place shows parallelism with the literature. The family factor in the effect of the social environment is undeniable. Although it varies according to age groups, the attitude of the family towards students is another factor affecting exam anxiety. There is a relationship between exam anxiety levels and parental attitudes (Duman, 2008). The attitude of the family will positively or negatively affect students's self-perceptions. Social and physical characteristics of the school include the physical equipment of the school, academic, sports and artistic achievements, and activities for parents and students (Nartgün \& Kaya, 2016). The more social and physical characteristics of the school are, the better and the more effectively the students will be able to prepare for the exams. As students become successful, their perceptions of themselves will tend to improve. All these factors are like a cycle. In future studies, the relations of these listed factors with each other or with other factors that are thought to be related should be searched. To sum up, as a result of our study, of the factors which affect exam anxiety the most, the social and physical characteristics of the school is in the first, how students see themselves is in the second, the thought of failing in the lessons is in the third, and the effect of the social environment is in the fourth place, which shows a parallelism with the literature.

The two factors that students think affect exam anxiety the least are teacher attitudes and the thought of not being prepared for exams adequately. Undesirable study habits, high 
expectations in exams, failing in responsibilities, family expectations and the fear that the level of intelligence will be evaluated by exam success are the reasons for exam anxiety (McDonald, 2001). When the literature is analyzed, it is seen that these two factors are among the variables that predict exam anxiety, but similar to the study, they are not important predictive variables.

This study includes a randomly selected study group consisting of 100 students. The scaling study is limited to six factors: the thought of failing in the lessons, the effect of the social environment, students's self-perceptions, teacher attitudes, the social and physical characteristics of the school, and the thought of not being prepared for the exams adequately. In future studies, the number of factors can be increased or different results can be obtained by using different factors. As a result of the research, it was seen that the two factors, the thought of failing in the lessons and the effect of the social environment, were interdependent. It is thought that it would be more beneficial to exclude one of these factors from the study. Considering these opinions, one of these two factors can be eliminated in future studies and different factors can be taken into consideration instead. The study group of this study consists of 8 th grade students. Scaling study can be done at different education levels. Within the scope of the results of the study, it is possible to help students control their exam anxiety by providing group guidance on the factors that stand out and by making programs to cope with exam anxiety. In the study, scaling was analyzed in terms of exam anxiety. The importance of the results should be analyzed and practical measures should be taken in the education process. Both classroom guidance teachers and psychological counselors should carry out preventive studies in schools. In future studies, according to the results obtained in this study, scale development studies can be conducted on test anxiety and the factors affecting academic success. In addition, studies can be carried out with other scaling methods in different psychological or sociological subject areas.

\section{Declaration of Conflicting Interests and Ethics}

The authors declare no conflict of interest. This research study complies with research publishing ethics. The scientific and legal responsibility for manuscripts published in IJATE belongs to the authors.

\section{Authorship Contribution Statement}

Hasibe Yahsi Sari: Investigation, literature review, visualization, data analysis, and writingoriginal draft. Duygu Anil: Research design, supervision, and validation.

Orcid

Hasibe Yahsi Sari (iD https://orcid.org/0000-0002-0451-6034

Duygu Anil (D) https://orcid.org/0000-0002-1745-4071

\section{REFERENCES}

Anil, D., \& Inal, H. (2017). Scaling Applications in Psychophysics. Pegem Academy.

Anil, D., Taymur, M. O., \& Oztemur, B. (2017). Scaling of the factors that are thought to be effective on the university preferences of the last grade students of high school by means of paired comparison method. Trakya Üniversitesi Eğitim Fakültesi Dergisi, 7(1), 75-85.

Aydın, U., \& Bulgan, G. (2017). Adaptation of children's test anxiety scale into Turkish: Validity and reliability study. Elementary Education Online, 16(2), 887-899. https://doi.org/10.17051/ilkonline.2017.304742

Bacanl, F., \& Sürücü, A.G.M. (2006). An examination of the relationship between test anxiety and decision making styles of elementary school 8th grades students. Educational Administration: Theory and Practice, 45(45), 7-35.

Basol, G., \& Zabun, E. (2014). The predictors of success in turkish high school placement exams: exam prep courses, perfectionism, parental attitudes and test anxiety. Educational 
Sciences: Theory and Practice, 14(1), 78-87. https://doi.org/10.12738/estp.2014.1.1980

Basol, G. (2017). IDA test anxiety scale: Validity and reliability study. The Journal of International Education Science, 4(13), 173-193. https://doi.org/10.16991/INESJOURN AL.1506

Bozanoglu, I. (2005). The effect of a group guidance program based on cognitive-behavioral approach on motivation, selfesteem, achievement and test anxiety levels. Ankara University Journal of Faculty of Educational Sciences, 38(1), 17-42. https://doi.org/10.1 501/Egifak 0000000110

Bulut, S.S. (2010). The effects of solution-focused brief group therapy on the treatment of exam anxiety, aggression tendencies and inadequacy in problem solving skills of secondary school students. Gazi University Journal of Gazi Educational Faculty, 30(2), 325-356.

Büyüköztürk, S., Kılıc Cakmak, E., Akgün, Ö.E., Karadeniz, S., \& Demirel F. (2008). Scientific research methods. Pegem Academy.

Cakmak, A., Sahin, H., \& Akinci-Demirbas, E. (2017). The analysis of relationship between test anxiety and self-esteem in the case of 7 th and 8th grade students. Kafkas University, e-Kafkas Journal of Educational Research, 4(2). https://doi.org/10.30900/kafkasegt.315 $\underline{182}$

Coban, S. (2009). The relationship of social environment's effects with juvenile delinquency and problem behaviours (Publication No. 315049) [Doctoral dissertation, Hacettepe University]. National Thesis Center. https://tez.yok.gov.tr/UlusalTezMerkezi/tezSorguS onucYeni.jsp

Delioglu, H.N. (2017). $8^{\text {th }}$ grade students of success of mathhematics and test and mathematics anxiety, mathematics self efficacy of investigation (Publication No. 454808) [Master's thesis, Adnan Menderes University]. National Thesis Center. https://tez.yok.gov.tr/Ulus alTezMerkezi/tezDetay.jsp?id=ujzt86YZJ_iUP-fpWDH_MQ\&no=AE31luBlryE0pZNS -qPPOQ

Driscoll, R. (2007). Westside test anxiety scale validation. Education Research Information Center. Retrieved from https://eric.ed.gov/?id=ED495968

Duman, G.K. (2008). An Examination of the Relationship Between State - Trait Anxiety Levels, Test Anxiety Levels and Parental Attitudes in the 8th Grade Primary School Students (Publication No. 220337) [Master's thesis, Dokuz Eylül University]. National Thesis Center. https://tez.yok.gov.tr/UlusalTezMerkezi/tezSorguSonucYeni.jsp

Genc, Y. (2016, August 24-26). Factors affecting exam anxiety of students preparing for university exam [Conference presentation]. In ICPESS, İstanbul,Turkey.

Guilford, J.P. (1954). Psychometric Methods. McGraw Hill Inc.

Güler, D., \& Cakir, G. (2013). Examining predictors of test anxiety levels among 12th grade high school students. Turkish Psychological Counseling and Guidance Journal, 4(39), 82-94.

Hembree, R. (1988). Correlates, causes, effects, and treatment of test anxiety. Review of Educational Research, 58(1), 47-77. https://doi.org/10.3102/00346543058001047

Kavakci, Ö., Güler, A.S., \& Cetinkaya, S. (2011). Test anxiety and related psychiatric symptoms. Journal of Clinical Psychiatry, 14(1), 7-16.

Kayapinar, E. (2006). Research into anxiety level of the 8th grades students at primary schools preparing for secondary school student selection and placement examination (The sample of Afyonkarahisar city) [Master's thesis]. Afyon Kocatepe University. https://tez.yok.gov.tr/UlusalTezMerkezi/tezDetay.jsp?id=mD s2fD2RrL4dDOaXEyq A\&no=hv0DeEk7ECSiHlhNYWqsFA

Kaya, M., \& Savrun, B.M. (2015). Relationship between attachment styles and test anxiety of students who will take the common exam for transition to secondary education system. Journal of New Symposium, 53(3), 32-42. https://doi.org/10.5455/NYS.20151215070858 
Kesici, A., \& Asilioglu, B. (2017). Developing stress scale for secondary school students: reliability and validity study. Kastamonu Education Journal, 25(6), 2413-2426.

Mandler, G., \& Sarason, S. B. (1952). A study of anxiety and learning. The Journal of Abnormal and Social Psychology, 47(2), 166-173. https://doi.org/10.1037/h0062855

McDonald, A.S. (2001). The prevalence and effects of test anxiety in school children. Educational Psychology, 21(1), 89-101. https://doi.org/10.1080/01443410020019867

Nartgün, Ş., \& Kaya, A. (2016). Creating school image in acccordance with private school parents' expectatons. Journal of Research in Education and Teaching, 5(2), 153-167.

Speilberger, C.D. (1980). Manual For-State Trait Anxiety Inventory. California Consulting Psychologisis Press.

Thurstone, L.L. (1927). A law of comparative judgment. Psychological Review, 34(4), $273-$ 286. https://doi.org/10.1037/h0070288

Totan, T., \& Yavuz, Y. (2009). The validity and reliability study of the turkish version of westside test anxiety scale. Mehmet Akif Ersoy University Journal of Education Faculty, 9(17), 95-109.

Tugan, S.E. (2015). Relationship between test anxiety and academic achievement. Karaelmas Journal of Educational Sciences, 3(2). 98-106.

Turan Başoğlu, S. (2007). The relationship between the pre-exam anxiety and the selfconfidence and to search the effects of those oncepts on the neolagnium (Publication No. 217683) [Master's thesis, Maltepe University]. National Thesis Center. https://tez.yok.gov.tr/UlusalTezMerkezi/tezSorguSonucYeni.jsp

Turgut, M.F., \& Baykul, Y. (1992). Scaling techniques. ÖSYM Press.

Wren, D.G., \& Benson, J. (2004). Measuring test anxiety in children: Scale development and internal construct validation. Anxiety, Stress \& Coping, 17(3), 227-240. https://doi.org/1 $\underline{0.1080 / 10615800412331292606}$

Yelken, R. (2011). The central institution in the prevention of juvenile delinquency is the family: Analysis of international conventions on children. Hancerli, Sevinc, Gürer \& Oner (Ed.), Driven to Crime and Victims Children (1st ed., pp. 32-41). SABEV Press.

Zeidner, M. (1998). Test anxiety: The state of the art. Plenum Press. 